\title{
A VIABILIDADE DE RESSOCIALIZAÇÃO DOS PEDÓFILOS À LUZ DO DIREITO INTERNACIONAL DOS DIREITOS HUMANOS
}

\author{
Rafaela Oliveira Reis Cadó ${ }^{351}$ \\ Yara Maria Pereira Gurgel ${ }^{352}$
}

Recebido em: 30/11/2016

Aprovado em: 20/03/2017

\begin{abstract}
RESUMO
A pedofilia é uma problemática séria enfrentada nos dias de hoje, principalmente com o advento da tecnologia, que se constitui o ambiente mais propício para esses indivíduos se esconderem. A sociedade, inclusive o judiciário, tem uma visão distorcida da pedofilia e acredita que qualquer abusador de crianças é pedófilo o que não é verdade. Necessário se faz a compreensão mais adequada da temática para que Estado possa fazer a abordagem mais acertada e eficiente. $\mathrm{O}$ ponto nevrálgico dessa situação é que a pena privativa de liberdade não possui o efeito reparador a esses indivíduos, uma vez que não se tratam de meros pervertidos, mas de pessoas com um problema psiquiátrico intenso que bloqueia a sua autodeterminação. Nesse sentido o melhor artificio para a reabilitação desses sujeitos é o tratamento multidisciplinar com médicos de diversas especialidade e um profissional psicólogo, junto com tratamento medicamentoso, devendo inclusive a sociedade e o Estado estar receptivo à apreciação de novas saídas como a castração química.
\end{abstract}

Palavras-chave: Pedofilia. Ressocialização Dignidade Humana. Direitos Humanos. Direito Constitucional.

\section{INTRODUÇÃO}

Não temos como questionar a condição globalizada em que vivemos hoje. A revolução digital já nos alcançou a muito tempo e não temos como retroceder nesse sentido. Somos reféns das redes sociais e da disseminação das informações, e é nesse contexto que os nossos filhos

\footnotetext{
351 Mestranda em Direito Constitucional, subárea Direito Internacional pela UFRN. Especialista em Direito Constitucional pela UFRN (2015). Advogada.

352 Doutora e mestre em Direito pela Pontifícia Universidade Católica de São Paulo - PUC/SP. Professora do Programa de Pós-graduação em Direito da UFRN. Advogada.
} 
são formados. Os abusos contra as crianças não surgiram agora, mas ganharam nova conotação. A internet, apesar de todas os estudos travados, ainda pode ser compreendida como uma "terra de ninguém", posto que ao mesmo tempo que facilita a comunicação, esconde o rosto do seu emissor.

Nossa conjuntura atual constitui-se terreno fértil para a atuação desses indivíduos que vivem à margem da sociedade, sociedade está que não o compreende e só o acusa. A condição de ser humano não some, só por um indivíduo estar doente, ou ser um criminoso, muito pelo contrário, perdura enquanto vida ele tiver.

O Estado, ademais, tem o seu direito de punir limitado à manutenção das condições mínimas da dignidade do criminoso. Também, resta importante compreender que a função da punibilidade exercida pelo Estado não pode ser a pena por si só, apenas com o intuito de prejudicar e de causar dor e sofrimento, mas o de tornar o criminoso apto a voltar para a sociedade.

Inclusive, pode-se dizer que a única forma de se justificar a dignidade da pena é tendoa com o objetivo de ressocializar o indivíduo, retirá-lo da margem e reinseri-lo como agente ativo da sociedade. Ocorre que, o pedófilo não é apenas um criminoso, mas um criminoso que, pelo advento da sua doença pratica atos criminosos. Assim, é fácil perceber que o agir criminoso está diretamente ligado à doença. Fato mais grave ainda é a incurabilidade atribuía aos portadores dessa parafilia. Assim, como abordar essa temática de forma a conseguir efetividade da pena e alcançar a ressocialização do pedófilo?

Essa é a questão mais pungente da temática, posto que se o indivíduo ficar preso sem o tratamento adequado, no mesmo instante em que for colocado de volta ao convívio social, voltará impreterivelmente a delinquir. Logo, todas essas temáticas são de grande valia e importância para o equilíbrio social e deve ser abordado da forma mais urgente possível, para que nem as crianças fiquem expostas, nem o pedófilo fique sem a assistência devida.

\section{O PEDÓFILO, A PEDOFILIA E SUAS CARACTERÍSTICAS IMPORTANTES}

Hodiernamente, à medida que a revolução digital se consolida por meio dos avanços da tecnologia, principalmente com o advento da internet, gradativamente se percebe a presença perniciosa da pedofilia. Todavia, apesar da perceptível evolução da legislação vigente, no Brasil, principalmente com a promulgação da Lei 11.829/2008 (Estatuto da criança e do 
Adolescente), compreende-se ainda, um atraso quanto efetivação das penas e a ressocialização desses indivíduos.

A pedofilia é a perversão sexual, na qual a atração sexual de um indivíduo adulto ou adolescente está dirigida primariamente para crianças pré-púberes (ou seja, antes da idade em que a criança entra na puberdade) ou no início da puberdade. A palavra pedofilia vem do grego $\pi \alpha \iota \delta$ o $\varphi \imath \imath \iota \alpha$ (paidophilia) onde $\pi \alpha \iota \varsigma$ (pais, "criança") e $\varphi \imath \lambda \iota \alpha$ (philia, "amizade", "afinidade", "amor", "afeição", "atração", "atração ou afinidade patológica" ou "tendência patológica"). (FERREIRA, 1993, p. 198)

Segundo a American Psychiatric Association, no Manual Diagnóstico e Estatístico de Transtornos Mentais, a pedofilia consiste em um transtorno sexual, inserido no grupo das parafilias, incluindo um padrão de excitação, desejos e fantasias sexuais, recorrentes e intensas (por, no mínimo, 6 meses), preferencialmente por crianças pré-púberes. A patologia não tem cura e é geradora de intenso sofrimento clínico com prejuízo no funcionamento social ou ocupacional ou em outras áreas importantes da vida do indivíduo. O mínimo de idade de um pedófilo é 16 anos, desde que seja pelo menos cinco anos mais velho que a criança alvo da pratica. (BÖHM, 2012, p. 11)

Desta feita, em observância à DSM-IV percebe-se que, hodiernamente houve uma banalização do termo pedofilia, confundindo-o e muitas vezes ofertando a ele valores descabidos. $\mathrm{O}$ conceito de pedofilia constitui-se um conceito médico, enquanto o conceito de abuso sexual é um conceito sócio jurídico uma vez que influencia a sociedade e imputa ao sujeito, via de regra, um crime. Assim, pode-se concluir que o termo pedofilia adentra o conceito abuso sexual infantil sem, contudo, se confundir com ele.

Assim, antes de mais nada, verifica-se de suntuosa importância a compreensão da pedofilia e a sua engrenagem dentro da mente humana e, acima de tudo, onde corre o seu aspecto patológico e o seu âmbito delituoso. No percurso do estudo percebe-se que muitas são as situações em que abusos sexuais ocorram sem que seja caso de pedofilia e para se compreender tal situação é necessário traçar o perfil do pedófilo.

Primeiro há que se compreender que a pedofilia é um tipo de parafilia a qual nada mais é do que o comportamento sexual fora do padrão. A pedofilia também está inserida como modalidade de abuso sexual, junto com o estupro, o assédio sexual e a exploração sexual profissional.

O portador da pedofilia tem, via de regra, fascinação ou interesse fora do normal por crianças, fazendo frequentes referências a santidade e pureza delas. A moradia desses 
indivíduos apresenta passatempos ou interesses em coisas que pertencem ao mundo infantil, como colecionar brinquedos, aeromodelismo e similares. O quarto é decorado com temas infantis e frequentemente o tema escolhido finda por revelar a idade preferida das crianças que molesta. Na maior parte dos casos apresenta mais de 30 anos, é solteiro e tem poucos amigos ou até nenhum, além de mudar de endereço com frequência. (CASOY, 2008, p. 31-32.)

$\mathrm{O}$ acesso à vítima se realiza de forma sistemática e prolongada, pois, logo levantaria suspeitas se não tivesse uma razão plausível para estar perto dos infantes. É usual que escolha empregos em setores em que estará forçosamente lidando com crianças em bases diárias, como professores, motoristas escolares, dentre outros. Outra característica comum é serem voluntários para atividades que ficarão sozinhos com crianças, sem supervisão dos pais.

Crianças saudáveis e com relacionamento familiar forte não estão totalmente livres de serem vítimas de molestadores, contudo as crianças problemáticas são alvos mais contundentes, uma vez que ninguém está próximo a elas para perceber qualquer situação diferente.

O pedófilo como sujeito pode ser enquadrado, primeiramente dentro de dois grandes grupos: os pedófilos abusadores e os pedófilos molestadores. Os abusadores são portadores de atitudes mais singelas, buscam por meio da amizade e da atenção ganhar a confiança da vítima. Observam-na, acariciam-na com delicadeza, ficando inclusive difícil de ser enxergado pela criança como abusador. Noutro giro, tem-se a categoria dos pedófilos molestadores que se subdivide em molestadores situacionais e molestadores preferenciais.

Os pedófilos molestadores situacionais apresentam inteligência inferior, baixa classe econômica. Além disso, podem possuir transtornos de personalidade como: psicopatia antissocial, narcisismo e esquizofrenia. Possuem comportamento criminal variado, gostam de pornografia violenta e apresentam impulsividade na atuação criminosa. Pode agir espontaneamente ou de forma planejada de acordo com a disponibilidade, oportunidade, ferramentas e aprendizado (SERAFIM, 2014, p. 04-05). São tidos como falsos pedófilos, uma vez que não são portadores da pedofilia parafílica, entretanto, podem apresentar outro tipo de distúrbio psiquiátrico ${ }^{353}$.

\footnotetext{
${ }^{353}$ Apesar de abusar sexualmente de crianças, elas não são o seu alvo principal, algumas vezes o estopim do abuso nem mesmo é de origem sexual. Na verdade, esses indivíduos praticam o gênero abuso sexual infantil, mas não podem ser considerados pedófilos, uma vez que não se enquadram na definição prevista no DSM-IV-TR. Esses indivíduos são oportunistas, quando percebem uma situação em que uma criança fica vulnerável se aproxima dela e faz o mau, pode estar eivado de um sentimento de estresse extremo. Essa espécie ainda pode ser dividida em quatro subespécies quais são: pedófilo molestador situacional regredido, inescrupuloso moral, inescrupuloso sexual e inadequado.
} 
Já os pedófilos molestadores preferenciais ${ }^{354}$ apresentam inteligência superior e advém de alta classe socioeconômica. Apresentam parafilia do tipo pedofilia que pode ser associada a mais alguma outra como voyeurismo e sadismo. Detém comportamento criminal focado, já que o objetivo deles sempre se volta para um infante, para tanto só gostam de pornografia infantil e agem sempre compulsivamente, muitas das vezes não conseguem controlar o seu ímpeto. (SERAFIM, 2012, p. 04-05)

\section{O PEDÓFILO PELA ÓTICA DO DIREITO INTERNACIONAL DOS DIREITOS HUMANOS}

Não é de hoje que se percebe, cada vez mais, a internacionalização das relações, principalmente políticas e econômicas, em todo o mundo. Nesse ínterim, as conexões entre Estados, nações e indivíduos na ordem internacional, com o consonante desenvolvimento dos princípios de Direito Internacional Público elevaram o patamar do tema "Direitos Humanos".

Todavia, o Direito Internacional dos Direitos Humanos surge, ainda em meados do século XX, por força da Segunda Guerra Mundial, e sendo impulsionado pelo execrável comportamento de Hitler que violava grandiosamente os direitos básicos do ser humano. Tais atrocidades deixaram a culposa sensação de que tais atos poderiam ser evitados pela existência de um sistema protetivo.

O Direito Internacional dos Direitos Humanos constitui-se o conjunto de normas internacionais, além de procedimentos e instituições criadas para implementar esta concepção e promover o respeito dos direitos humanos em todos os países. No DIDH ocorre a responsabilização dos Estados por violações de Direitos Humanos, relativizando, pois, a soberania dos Estados, e consolidando o reconhecimento definitivo de que a pessoa humana é sujeito de direito em âmbito internacional. Assim, todas as nações e a comunidade internacional têm o direito e a responsabilidade de protestar, se um Estado não cumprir suas obrigações.

A consolidação e o desenvolvimento do Direito Internacional no pós-Segunda Guerra Mundial obrigam a revisão da teoria clássica de soberania ao impor aos Estados e seus governantes o respeito aos Direitos Humanos. Assim, o Direito Internacional dos Direitos

\footnotetext{
${ }^{354} \mathrm{O}$ pedófilo molestador preferencial apresenta três subespécies: o sedutor, o introvertido e o sádico. O sedutor tem como traços básicos cortejar as suas vítimas com presentes, atenção e afeto. Costuma seduzir suas vítimas por um período prolongado, apresenta habilidades para identificar-se com crianças, sabe escutar e dialogar, conseguindo, assim criar um vínculo com elas. Aproveita-se da sua autoridade e condição de adulto e conseguem manter várias vítimas simultaneamente pela sua forma mais discreta de atuação.
} 
Humanos passa a ser parâmetro limitador da atuação dos Estados no que se refere as sanções penais. Assim o DIDH, por meio do seu corpo normativo é balizador do poder punitivo, traçando parâmetros e exercendo, efetivamente, restrição ao poder punitivo do Estado.

Ao tratar desse tema Flavia Piovesan (2012, p. 29) afirma que o movimento do direito internacional dos direitos humanos fundamenta-se no contexto de que toda nação tem a reponsabilidade e obrigação de respeitar e priorizar os direitos humanos de seus pares; e de que todas as nações e a comunidade internacional têm o direito e a responsabilidade de protestar, se um Estado desrespeitar esses parâmetros.

Assim, ainda com fulcro no que trata Piovesan (2012, p 29), pode-se dizer que o Direito Internacional dos Direitos Humanos consiste em um sistema de normas internacionais, procedimentos e instituições desenvolvidas para implementar esta concepção e promover o respeito dos direitos humanos em todos os países, no âmbito mundial.

Nesse mesmo contexto histórico, surge a Declaração Universal com o significado de um código uniformizador da conduta das nações. A Declaração consolida a afirmação de uma ética universal, ao consagrar um consenso sobre valores de cunho universal a serem seguidos pelos Estados. A concepção de universalidade surge porque a única condição que unifica todos em qualquer lugar do mundo é a condição de pessoa, assim, esse é o requisito único, exclusivo, portanto universal para a titularidade de direitos, surgindo aí a dignidade humana como fundamento dos direitos humanos. (PIOVESAN, 2012, p. 29)

A Declaração Universal dos Direitos Humanos foi o marco para o Direito Internacional e, sobretudo, para o Direito Internacional dos Direitos Humanos, visto que, como explanado, formula a noção irmã e universal da dignidade humana. Em consequência da Declaração Universal surgem diversos tratados internacionais, visando à proteção dos direitos humanos.

Nesse sentido corre a Convenção Americana sobre direitos humanos, mais conhecido como Pacto de San José da Costa Rica que em seu preâmbulo afirma:

Reconhecendo que os direitos essenciais do homem não deviam do fato de ser ele nacional de determinado Estado, mas sim do fato de ter como fundamento os atributos da pessoa humana, razão por que justificam uma proteção internacional, de natureza convencional, coadjuvante ou complementar da que oferece o direito interno dos Estados americanos; (ORGANIZAÇÃO DOS ESTADOS AMERICANOS, 2014)

A dignidade é composta por um conjunto de direitos existenciais compartilhados por todos os homens, em igual proporção. Partindo dessa premissa, contesta-se aqui toda e qualquer ideia de que a dignidade humana encontre seu fundamento na autonomia da vontade. A titularidade dos direitos existenciais, porque decorre da própria condição humana, independe 
até da capacidade da pessoa de se relacionar, expressar, comunicar, criar, sentir. O único requisito para se ter direito à dignidade constitui-se a condição humana, assim, não se condiciona à moral ou ao comportamento. Logo, a dignidade é sempre mantida, mesmo que cometam as maiores atrocidades. (GURGEL, 2008, p. 39)

Assim, por mais que o indivíduo se encontre limitado física ou psicologicamente, não perde a sua essência de ser humano. Desta feita, os indivíduos inimputáveis, por problemas psiquiátricos, independentemente da sua gravidade, permanecem no contexto humano, não havendo, jamais, redução da sua capacidade de pertencer a raça humana. Logo, a condição humana em nada tem a ver com o poder de autodeterminação do indivíduo, assim, por mais que o indivíduo perca o poder de se determinar, continua sendo humano e merecendo dignidade. Nesse sentido discorre o brilhante Ingo Sarlet (2002, p. 50) que afirma, "mesmo aquele que já perdeu a consciência da própria dignidade merece tê-la (sua dignidade) considerada e respeitada."

O Princípio da Dignidade da Pessoa Humana apresenta dois pilares: a igualdade e a liberdade. A Declaração Universal dos Direitos Humanos, põe em destaque, já a partir do seu primeiro princípio, esses pilares quando afirma que "todas as pessoas nascem livres e iguais em dignidade e direitos. São dotadas de razão e consciência e devem agir em relação umas às outras com espírito de fraternidade. " (ORGANIZAÇÃO DAS NAÇÕES UNIDAS, 2015)

No que tange a igualdade, temos que levar em conta o princípio da igual consideração de interesses que consiste em valorizar o interesse alheio nos mesmos termos que valorizamos os nossos próprios interesses. Destarte, exaltar o conceito de solidariedade consiste em valorizar o outro para preservação da sociedade. Nesse ínterim, defender o interesse alheio é o mesmo que defender seu próprio interesse. Assim, a compreensão da dignidade humana, com fulcro na igualdade é a solidariedade vista como uma maneira de se defender coletivamente. (COMTESPONVILLE, 2002, p. 32)

A liberdade é o outro pilar que formata a base do princípio da dignidade humana. A liberdade aqui será considerada em sua concepção mais ampla, ou seja, constitui-se a permissão ao homem exercer plenamente os seus direitos existenciais. Na verdade, a liberdade ampla nada mais é do que o poder inerente a cada ser humano de se autodeterminar e escolher os caminhos a seguir, ou seja, os seus sonhos, os seus desafios, as suas escolhas e os seus parâmetros. Vale salientar, todavia, que a liberdade possui limites e eles se baseiam exatamente na igualdade dele com o seu par, ou seja, a minha liberdade mora onde a liberdade do outro reside. 
Assim, o indivíduo deve ser livre para fazer suas próprias escolhas, desde que isso não prejudique diretos de terceiros. Todo o indivíduo deve ser livre para desenvolver todas as suas potencialidades. Deve, para tanto, fazer suas escolhas em critérios subjetivos que atendam a seu próprio conceito de felicidade, contudo deve ter como limite os direitos de terceiros. A autonomia, em respeito aos direitos humanos e ao princípio da dignidade humana deve ser protegida com a garantia de um amplo espaço aos indivíduos, contra a ingerência excessiva do Estado, postulando o que deve ser feito.

$\mathrm{Na}$ verdade, a luta pelos direitos humanos foi sempre a luta pelo reconhecimento da dignidade da pessoa humana, em suas múltiplas facetas. A amplitude da polissemia da expressão "dignidade da pessoa humana" impede que se atribua a ela um conceito fixo, ainda que aberto. Há, contudo, um núcleo mínimo de sentido para a dignidade da pessoa humana, para que cada um tenha o direito de ser respeitado como ser humano que é visto com igualdade; outro ponto nevrálgico para a compreensão da dignidade humana é o poder de autonomia e autodeterminação, assim, o ser humano realiza suas próprias opções em busca de sua felicidade.

$\mathrm{Na}$ nossa Constituição a dignidade humana é expressa como princípio fundamental. Significa que os direitos fundamentais garantem ao indivíduo ser quem ele é e isso não pode acarretar perseguições, sanções. A dignidade não permite ao Estado punir alguém pelo que ele é, só pelo o que ele faz. Tal situação foi importante para abolir da esfera penal a responsabilidade objetiva. Fazer tal afirmação significa dizer que a pessoa só pode sofrer sanções quando faz algo e apenas quando essas atitudes violarem direito de terceiros. É uma consequência da própria autonomia da pessoa. (ANDRADE, 2015)

Cabe a nós avaliar todo esse contexto tendo em vista a conceituação já tratada do pedófilo e da pedofilia. Assim, o indivíduo que é portador da parafilia deve ser compreendido não como doente ou como criminoso, mas como ser humano, que o é. Independentemente de toda problemática que envolve o pedófilo, ele não perde a sua característica humana e deve ser preservado como tal. Assim, muito importante apreciar a dinâmica para que nem os terceiros, diga-se crianças, fiquem em risco, nem o pedófilo seja enclausurado sem perspectiva de ressocialização, sendo obrigado de todas as formas a viver a margem da sociedade.

Desta feita, difícil é a situação a qual é posta a sociedade, uma vez que deve colocar em questão a violação da dignidade humana de uma forma ou de outra. Em um momento, quando permite a liberdade de indivíduos que ofertam iminente perigo a crianças, seres totalmente indefesos. Noutro, quando encarcera um indivíduo doente, sem possibilidade de readequação social, devendo, para detê-lo, mantê-lo em prisão perpetuamente, o que, como muito se sabe, 
não é permitido. Assim, deve ser feita a ponderação entre o direito fundamental do criminoso de não ser submetido à prisão perpétua e à penas cruéis e degradantes, e o direito fundamental à vida, à integridade física e à dignidade das crianças e dos adolescentes Assim, resta saber: como deve agir o Estado?

O caminho deve ser proteger um indivíduo, diante da égide do Direito Internacional dos Direitos Humanos, fundamentado essencialmente dela Dignidade da Pessoa Humana, avalialo, ao mesmo tempo que igual como ser humano, diferente por ser único e insubstituível. Assim, a sua doença deve ser enxergada antes mesmo do seu delito, pois aquela apresenta-se como a causadora desta última. Destarte, imperioso se faz o envolvimento do Estado de forma a abordar a situação de forma multidisciplinar, já que sem o devido tratamento o poder de autodeterminação dos pedófilos mostra-se totalmente descontrolado.

\section{A EFETIVIDADE dAS PENAS DIANTE dOS PEDÓFILOS}

As penas aplicáveis aos pedófilos, tendo em vista o seu caráter criminoso, isoladamente, acabam por se tornar ineficazes. Tal situação advém do caráter dúplice da pedofilia que deve ser enxergada, primeiramente, como doença para só então ser avaliado o seu viés criminológico. Assim, a pena restritiva de liberdade, isoladamente, como comumente ocorre, para esses indivíduos, não apresenta nenhuma efetividade uma vez que não consegue atingir o fim maior de toda e qualquer pena que é a ressocialização.

Muito se sabe que, até mesmo pelo caráter patológico da pedofilia, muito difícil é a viabilidade da ressocialização desses indivíduos. A prisão, por si só, faz apenas uma limitação física desses indivíduos, assim quando eles retornam ao convívio social, imediatamente voltam a delinquir. Essa situação, pode ser enxergada inclusive como inevitável, já que não existe pena perpétua.

A norma jurídica, no que tange ao Direito penal, impõe a sua conduta e o seu cumprimento pelo artifício da ameaça, levando o sujeito a pensar nas consequências antes de agir contrariamente aos valores impostos. A atuação do Direito Penal tem como objetivo maior a segurança jurídica por meio da proteção dos bens jurídicos essenciais.

O direito penal ampara os bens jurídicos mais importantes da sociedade, sem os quais a sociedade arruína-se. Atua selecionando os comportamentos humanos mais graves e perniciosos à coletividade, capaz de destruí-la, colocando em risco os valores fundamentais 
para a convivência social. Depois de selecionar essas atitudes agressivas, descrevê-las-á como infrações penais que gerarão consequências e respectivas sanções. (CAPEZ, 2011, p. 19)

O direito penal, no brasil, sempre apresentou uma feição clássica: tutelar, fragmentaria e de intervenção mínima. De acordo com os conceitos tradicionais, a norma penal incriminadora visa a proteger os bens jurídicos fundamentais da sociedade. Não, porem de forma absoluta. Tem a seu cuidado somente os bens considerados mais relevantes. Assim, nem todos são plenamente resguardados. (JESUS, 2000, p. 3)

Exatamente por se preocupar apenas com os principais bens, mantenedores da harmonia social é considerado um direito de ultima ratio, visto que só deve ser utilizado em última instância, quando mais nenhum ramo do direito detém força para controlar a situação. Esse ramo tem autorização do Estado para punir as condutas castigáveis, valendo-se delas apenas quando não for mais possível a aplicação de outro tipo de direito. Destarte, é a sanção penal uma das principais características do Direito Penal e é ela que o diferencia dos demais ramos do Direito. ${ }^{355}$

É na consciência sobre a necessidade de se manter a ordem, para que a sociedade mantenha o seu equilíbrio, que se baseia a necessidade de punição e, consequentemente, o direito de punir. Logo, a pena é a consequência natural imposta pelo Estado quando alguém pratica uma infração penal, abrindo a possibilidade para o Estado fazer valer o ius puniendi. $\mathrm{O}$ ilustre Fernando Capez (2011, p. 28) se manifesta a respeito do conceito de pena:

Conceito de pena: sanção penal de caráter aflitivo, imposta pelo Estado, em execução de uma sentença, ao culpado pela prática de uma infração penal, consistente na restrição ou privação de um bem jurídico, cuja finalidade é aplicar a retribuição punitiva ao delinquente, promover a sua readaptação social e prevenir novas transgressões pela intimidação dirigida à coletividade.

A finalidade da pena pode ser explicada por meio de três teorias: a teoria absoluta ou da retribuição; a teoria relativa, finalista ou de prevenção; e a teoria mista, eclética, intermediaria ou conciliatória (CAPEZ, 2011, p. 385). Ao abordar tal tema Fernando Capez afirma ainda que:

O Direito Penal é muito mais do que um instrumento opressivo em defesa do aparelho estatal. Exerce uma função de ordenação dos contatos sociais, estimulando práticas positivas e refreando as perniciosas e, por essa razão, não pode ser fruto de uma elucubração abstrata ou da necessidade de atender a momentâneos apelos

\footnotetext{
${ }^{355} \mathrm{O}$ princípio dá intervenção mínima, ou ultima ratio, é o responsável não só pela indicação dos bens de maior relevo que merecem a especial atenção do Direito Penal, mas se presta, também, a fazer com que ocorra a chamada descriminalização. Se é com base neste princípio que os bens são selecionados para permanecer sob a tutela do Direito Penal, porque considerados como os de maior importância, também será com fundamento nele que o legislador, atento às mutações da sociedade, que com a sua evolução deixa de dar importância a bens que, no passado, eram da maior relevância, fará retirar do nosso ordenamento jurídico-penal certos tipos incriminadores. (GRECO, 2012, p. 47)
} 
demagógicos, mas, ao contrário, refletir, com método e ciência, o justo anseio social. (CAPEZ, 2011, p. 28)

Assim, na teoria retributiva quem faz o mal receberá o mal em troca, ou seja, a função é de "descontar" não pensa em ressocializar para que o ofensor não volte a agir. Nestes termos, a pena não apresenta fim, encontrando-se dissociada do fim. Já na teoria preventiva a pena passa a ter finalidade de prevenir que o ilícito venha a acontecer novamente; visa essencialmente a ressocialização do criminoso. Já a teoria mista, mistura num só corpo a teoria retributiva e preventiva, assim, a pena deve, além de punir o criminoso, prevenir a prática do crime, pela reeducação e pela intimidação coletiva.

O encarceramento, em contrapartida é concebido como principal pena aplicada no Brasil, inflando os presídios brasileiros e complicando ainda mais o que por si só já é complicado. A verdade é que a pena privativa de liberdade como sanção principal e de aplicação genérica está falida, uma vez que não readapta o delinquente que quando volta às ruas torna aos crimes e tende a mais uma vez retornar ao ambiente prisional, sendo esse um círculo vicioso que não tem fim. ${ }^{356}$

Damásio de Jesus (2000, p. 12) afirma que na situação em que nos encontramos hoje é necessária a utilização da prisão apenas para os crimes graves cometidos por delinquentes de extrema periculosidade. Nas demais situações as penas alternativas e restritivas de direito devem prevalecer.

A Organização das Nações Unidas, no IX Congresso da ONU sobre prevenção do crime e tratamento do Delinquente, realizado no Cairo (abril/maio de 1995), apresenta seu posicionamento nesse mesmo sentido, uma vez que recomendam a utilização de pena detentiva, ou seja, a privativa de liberdade, apenas em último caso, restrito ainda aos crimes graves que possuam como autores indivíduos de intensa periculosidade. Já no que se refere a outros delitos e criminosos de menor potencial ofensivo, medidas e penas alternativas devem ser largamente utilizadas. Dado importante deve ser considerado nesse posicionamento recomendado, uma vez que por meio de estática já fora comprovado que a reincidência é maior em relação aos condenados que cumpriram pena privativa de liberdade do que os que se submeteram às medidas alternativas. (JESUS, 2000, p. 13).

\footnotetext{
$356 \mathrm{O}$ primeiro problema que nos salta à vista é a superlotação nos presídios brasileiros. Uma CPI realizada em 2008 sobre o sistema prisional brasileiro calculou que existiam no país cerca de 440 mil presos, sendo que havia nos estabelecimentos vagas para apenas 260 mil. Ou seja, um déficit de 180 mil leitos! Não é raro encontrar presídios onde 60 pessoas dividem uma cela apropriada para no máximo 15 indivíduos
} 
Se a pedofilia se constitui uma doença, sendo compreendida até então como sem cura, a única solução viável para esse indivíduo é a pena privativa de liberdade. Todavia, a objetivo da punibilidade exercida pelo Estado é a reinserção dessa pessoa na sociedade e não apenas prender por prender ou prender para fazer sofrer. Assim, enquanto o indivíduo encontra-se preso não envereda pelo ato delituoso, mas como para ele, como já dito, falta a autodeterminação, no momento em que sua pena se finda e ele retorna para a rua, tudo começa outra vez. Assim, pode-se dizer que não há efetividade da pena privativa de liberdade, não pelo individuo continuar delinquindo enquanto preso, mas por inviabilizar a sua volta à sociedade.

\section{A POSSÍVEL RESSOCIALIZAÇÃO DOS PEDÓFILOS E A DIGNIDADE DA PESSOA HUMANA.}

Antes de mais nada, verifica-se de suntuosa importância a compreensão da pedofilia e a sua engrenagem dentro da mente humana e, acima de tudo, onde corre o seu aspecto patológico e o seu âmbito delituoso. Nesse contexto, ao avaliar a prática percebe-se a falta de efetividade dessas ações, uma vez que os pedófilos, via de regra voltam a agir, uma vez que não conseguem controlar o seu instinto. Assim, as formas vigentes de combate a essa conduta são inócuas.

Há que se levar em conta o aspecto verdadeiramente doentio dessa prática e nesse ínterim o mero encarceramento da figura do pedófilo não soluciona a problemática, posto que na primeira oportunidade encontrada, por meros aspectos hormonais, psicológicos e psiquiátricos, volta a delinquir.

A pedofilia em si, não encontra tipificação no Ordenamento Jurídico Brasileiro, até mesmo porque não configura propriamente um crime, mas um distúrbio sexual. O pedófilo, mesmo diagnosticado, não apresenta, de pronto, nenhuma ofensa à sociedade só por existir (direito penal do autor), contudo se produzir qualquer das atitudes tipificadas no Código Penal, Lei de Crimes Hediondos e Estatuto da Criança e do Adolescente deve ser punido.

A Constituição Federal de 1988, em seu artigo 227, caput e $\$ 4^{\circ}$, preconiza que deve ser assegurado à criança e ao adolescente, pela família, sociedade e pelo Estado, o direito à vida, à saúde, à alimentação, à educação, ao lazer, à profissionalização, à cultura, à dignidade, ao respeito, à liberdade e à convivência familiar e comunitária. Deve ainda ser colocada a salvo de toda forma de negligência, discriminação, exploração, violência, crueldade e opressão. Afirma 
ainda, tal artigo da Carta Maior, que a lei punirá severamente o abuso, a violência e a exploração sexual da criança e do adolescente.

A lei brasileira em sentido oposto ao que é comumente utilizado em outros países, não possui um tipo especial para a "pedofilia". Porém, enquadra-o em diversos outros tipos penais como nos crimes de estupro (art. $213 \mathrm{CP}$ ), assédio sexual (art. 216-A CP), estupro de vulnerável (art. 217-A CP), corrupção de menores (art. 218 CP), satisfação de lascívia mediante presença de criança ou adolescente (art. 218-A CP), dentre outros.

Contudo, é necessário se caracterizar penalmente a Pedofilia não como uma espécie de conduta, uma vez que as possíveis condutas de um pedófilo já estão formalizadas. Não existe crime sem ação, ou seja, para estar diante de um fato típico, antijurídico e culpável, deve haver uma conduta penalmente reprovável, porém, isso não ocorre com a pedofilia que sozinha não apresenta uma ação específica. Todavia, pelo próprio perfil da parafilia, sabe-se que em algum momento aquele indivíduo vai delinquir e recair sobre os atos já tipificados no ordenamento jurídico.

$\mathrm{Na}$ ordem jurídica vigente em nosso país, como dito, não há nenhum tipo penal específico relativo à conduta típica da Pedofilia, nem ao sadismo, ao voyeirismo, fetichismo ou qualquer outra parafilia, uma vez que o autor de uma conduta delituosa deve ser punido pelo que fez (direito penal do fato) e não pelo que é (direito penal do autor).

Existe, porém, um perigo nessa não definição da pedofilia nos termos legais, que é confusão que se faz entre o abusador sexual de crianças e o pedófilo. O que se procura na atualidade é a adequação do resultado exaurido pelas condutas dos portadores destas parafilias aos tipos penais existentes. O pedófilo não pode receber o mesmo tratamento que um pervertido normal recebe. Assim, é bastante obvio que apesar da pedofilia não ser crime, as atitudes praticadas pelo pedófilo o são, e devem ser punidas por isso. Entretanto, há de haver uma diferenciação entre um crime de estupro de vulnerável praticado por um pervertido e um estupro de vulnerável praticado por um pedófilo.

Essa sutil percepção que falta à lei e aos aplicadores da Lei e leva a uma sucessão de erros, uma vez que o Juiz ao aplicar a pena ao caso concreto não consegue visualizar a diferença, pelo próprio desconhecimento. Muitas vezes o indivíduo mesmo eivado de um distúrbio severo é enclausurado, sem direito, inclusive, a medida de segurança, por falta de avaliação do agente agressor por psiquiatra forense, perito profissional, com parecer técnico, dotado de conhecimento científico, que comprove sua sanidade mental, se pedófilo ou não. Como 
consequência dessa cadeia de erros o pedófilo mais cedo ou mais tarde volta às ruas, ainda mais perturbado em busca de uma nova vítima.

Assim, resta claro que hoje a dignidade desses indivíduos já se encontra à deriva, pois o próprio Estado não sabe fazer a abordagem adequada. Para que o agente possa ser responsabilizado por um crime por ele cometido é preciso que seja imputável. A regra é que os indivíduos sejam imputáveis, cabendo, contudo, a exceção da inimputabilidade. $\mathrm{O}$ artigo 26 do Código Penal define a inimputabilidade e afirma ser isento de pena o agente que era inteiramente incapaz de entender o caráter ilícito do fato ou de determinar-se de acordo com esse entendimento, ao tempo do crime, motivado por doença mental, desenvolvimento mental incompleto ou retardado. Se não totalmente inclinado nessa definição, poderá também ser parcialmente imputável, proporcionalmente ao seu problema, de acordo com análise psiquiátrica.

Nestes termos, quem se enquadrar nesse perfil valer-se-á de absolvição, ficando adstrito às medidas de segurança que tem função preventiva e busca afastar do convívio social o inimputável, senão vejamos o que fala a respeito Ana Selma Moreira (2010, p. 139):

A Medida de Segurança tem função preventiva e busca afastar o inimputável ou semi-
inimputável perigoso, devido ao seu distúrbio, do convívio social por tempo
indeterminado, pois tal medida só cessa quando não houver mais perigo. O caráter
perigoso se faz com a comprovação da qualidade sintomática de perigo (diagnóstico
da periculosidade); e depois a comprovação da relação entre qualidade e o futuro
criminal do agente (prognose criminal). Periculosidade pode ser verificada de maneira
real, quando o juiz verifica de acordo com o caso concreto, ou presumida, quando a
própria lei estabelece que determinado indivíduo deve ser submetido à Medida de
Segurança, sem necessidade de avaliação do perigo.

Conclui-se, que pela forma que se encontra disposto no ordenamento jurídico brasileiro, deve ficar, via de regra, encarcerado por meio de pena privativa de liberdade. Em casos excepcionais se sujeitará a medidas de segurança.

A pena privativa de liberdade, no caso sub examine, apresenta pouca efetividade, uma vez que o indivíduo continuará doente e assim que tiver oportunidade incorrerá no mesmo crime. Já a medida de segurança em seus parâmetros gerais pode oferecer melhores resultados aos pedófilos, uma vez que objetiva o tratamento por meio de medicamento, acompanhamento psicológico ou até internação. Todavia, os fármacos utilizados comumente para esses pacientes não oferecem boas respostas aos portadores dessa parafilia, assim, mais uma vez, esse sujeito poderia compulsivamente recair no crime.

O Estado, sem sombra de dúvidas precisa buscar novas soluções para abordar a situação. O método de Castração Química, ainda não autorizado no Brasil, mas já utilizado em outros 
países, como Estados Unidos e Itália vem ganhando muitos adeptos. A técnica consiste, de forma simplificada em ministrar doses de hormônio feminino com o intuito de reduzir a produção de testosterona (hormônio masculino). Não visa castrar, nem esterilizar a pessoa, apenas reduzir a libido, enquanto o medicamento está em uso.

Assim, os perigosos impulsos do criminoso sexual, em especial do pedófilo, são completamente tosados. Tais consequências não são definitivas e necessitam de continuidade, porém, enquanto utilizada, a técnica reduz a reincidência do crime de forma sensível. Tal método merece melhor análise pelas respostas apresentadas nos pacientes, posto que ao mesmo tempo que o anula diante das sensações sexuais, habilita-o a conviver com a sociedade, podendo aproveitar todos os outros aspectos que lhe eram tolhidos pela doença.

Conclui-se, destarte que pela forma que a situação vem sendo conduzida no pais, podese dizer que o pedófilo não vem sendo tratado nos parâmetros exigidos pelo Direito Internacional dos Direitos Humanos, tendo em conta a Dignidade Humana. André de Carvalho Ramos, citando Kant afirma que a dignidade da pessoa humana consiste que cada indivíduo é um fim em si mesmo, com autonomia para se comportar de acordo com seu arbítrio, nunca um meio ou instrumento para a consecução de resultados, não possuindo preço (RAMOS, 2014, p. 72).

É de claridez solar que atuação Estatal se dá de forma a conter o problema, momentaneamente, sem se preocupar com a essências dessas pessoas que já estão com suas vidas destruídas e não conseguem perceber a destruição que causam na vida de várias pessoas com o seu ato delituoso. Desta feita, não se pode ignorar as novas soluções trazidas pela ciência, principalmente se, pode-se inclusive pensar em reinserção na sociedade e na viabilidade de ressocialização do pedófilo.

\section{CONSIDERAÇÕES FINAIS}

O presente trabalho não teve o escopo de esgotar a temática, mas sim de trazê-la à tona para que possa ser mais discutida. Vivemos hoje num modelo prisional fracassado em que os presos são tratados de forma esdrúxula em condições piores do que a de muitos animais. Todavia, muito se sabe que para o equilíbrio social a pena privativa de liberdade é extremamente necessária, mas deve ser pensada uma melhor maneira de ressocializar os criminosos que ali entram. 
Pode-se dizer, inclusive que da maneira em que se encontra, a prisão é apenas uma vedação física temporária para que esses indivíduos possam não delinquir, sem contar com aqueles que conseguem delinquir até mesmo dentro dos presídios e cadeias públicas. No que tange especificamente aos pedofilos a situação é ainda mais complicada, posto que enquanto a doença não for cuidada, é impossível a ressocialização desse indivíduo. Ocorre que os fármacos usuais não exercem expressivos resultados isoladamente.

Primeiramente, e talvez o mais importante nessa situação é compreender a pedofilia enquanto parafilia, ou seja, enquanto doença. Na verdade, os abusadores de crianças nem sempre são pedófilos. Os pedófilos não são meros abusadores pervertidos que se aproveitam de uma oportunidade para atacar. Esses indivíduos têm sua vida completamente prejudicada, pois não conseguem, muitas das vezes sequer dormir sem ser assolados por pensamentos inescrupulosos.

Apesar de não se culparem muitas das vezes (em algumas vezes se culpam), têm consciência que o que fazem os tornam diferentes do resto do mundo e é assim que eles se sentem, completamente excluídos. Assim, por mais que tenham consciência do erro do ato em si, não conseguem o autocontrole, ou melhor, a autodeterminação para decidirem o que vão fazer. Essa definição, todavia, só uma equipe de médicos e psicólogos especializados para concluir caso a caso.

Contudo, a conclusão que se chega é que ainda existe muito desconhecimento sobre a temática, em todos os âmbitos da sociedade, principalmente no que tange aos juristas. O Estado necessita se portar de uma maneira que consiga manter a harmonia da sociedade, de forma equilibrada, e só conseguirá fazer isso se começar a compreender a pena como meio de ressocialização dos indivíduos.

No caso em questão é ainda mais complicado porque a prisão é um engodo e até pode piorar o caso, uma vez que os indivíduos saem, inclusive, piores do que entraram. Um tratamento humano, com uma equipe multidisciplinar, podendo valer-se do tratamento antagonista da testosterona, quando necessário, é a maneira mais digna de tratar esses indivíduos que não são meros monstros, são antes de tudo, seres humanos doentes.

\section{REFERÊNCIAS}


AMERICAN PSYCHIATRIC ASSOCIATION. Diagnostic and Statistical Manual of Mental Disorders-IV (Text Revision). Arlington, VA, USA: American Psychiatric Publishing, Inc., 2000-06. P. 566.

ANDRADE, André Gustavo Corrêa de. O princípio fundamental da dignidade humana e sua concretização judicial. Disponível em: http://portaltj.tjrj.jus.br/c/document_library/get_file?uuid=5005d7e7-eb21-4fbb-bc4d12affde2dbbe\&groupId=10136 . Acessado em: 20 nov. 2015.

ARIÈS, Philippe. A história social da criança e da família. Tradução de Dora Flasksman. $2^{\mathrm{a}}$ edição. Rio de Janeiro: LTC- Livros Técnicos e Científicos Editora S.A, 1981. Versão Digital. Disponível em: http://www.faroldoconhecimento.com.br/livros/Educa\%C3\%A7\%C3\%A3o/PHILIPPEARIES-Historia-social-da-crianca-e-da-familia.pdf. Acessado em: 10 nov. 2016.

AZAMBUJA, Maria Regina Fay de. Violência sexual intrafamiliar: é possível proteger uma criança? Revista Virtual Textos \& Contextos, $n^{\circ} 5$, página 3, Novembro de 2006. Disponível em: http://revistaseletronicas.pucrs.br/ojs/index.php/fass/article/view/1022. Acessado em: 13 nov. 2016.

AZEVEDO, Solange. Hormônios contra o Crime. Revista Época, 30 jul. 2008. Disponível em:

http://revistaepoca.globo.com/Revista/Epoca/0,,EMI5867115228,00HORMONIOS+CONTR A+O+ CRIME.html. Acessado em: 26 nov. 2016.

BALTIERI, Danilo. Pedofilia é doença? Revista Guia-me, 03 jun. 2009. Entrevistado por Adriana Amorim. Disponível em: http://www.guiame.com.br/noticias/vidaestilo/saude/pedofilia-e-doenca.html. Acessado em: 28 out. 2016.

BEGALLI, Ana Silvia Marcatto. Dignidade da pessoa humana e Direito Penal. Publicado em 04/2010. Disponível em: http://jus.com.br/artigos/14624/dignidade-da-pessoa-humana-edireito-penal\#ixzz3S9eYluyX. Acessado em: 20 out. 2016.

BITENCOURT, Cezar Roberto. Falência da Pena de Prisão: causas e alternativas. $2^{\mathrm{a}}$ ed. São Paulo: Saraiva, 2001.

BÖHM, Denise Müller. Características Emocionais e Comportamentais de Adolescentes e Adultos Suspeitos de Praticar Abuso Sexual. 2012. 42 f. monografia (mestrado em saúde e comportamento) - Universidade Católica de Pelotas, Pelotas/RS, p. 11. Disponível em: http://antares.ucpel.tche.br/ppgsaude/dissertacoes/Mestrado/2012/Denise\%20Muller\%20Boh $\mathrm{m} \% 20$ Caracteristicas $\% 20$ emocionais $\% 20 \mathrm{e} \% 20$ comportamentais $\% 20 \mathrm{de} \% 20$ adolescentes $\% 20$ 
e\%20adultos\%20suspeito\%20de\%20praticar\%20abuso\%20sexual.pdf. Acessado em 27 nov. 2016.

BRUTTI, Roger Spode. Tópicos Cruciais sobre Pedofilia. Revista IOB de Direito Penal e Processual Penal, Porto Alegre, ano VIII, n. 47, dez- jan./2008.

BUTLER, Sandra. A conspiração do silencio: o trauma do incesto. Edição Norte-Americana, publicada em 1978 por New Gilde Publications, Inc., São Francisco, Califórnia.

CAPEZ, Fernando. Curso de Direito Penal: Parte Geral. V. 1. $15^{\mathrm{a}}$ ed. São Paulo: Saraiva, 2011.

CASOY, Ilana. Serial Killer: louco ou Cruel? $8^{a}$ ed., ver. e ampl. São Paulo: Editora Ediouro, 2008.

CONTI, Matilde Carone Slaibi. Da pedofilia: aspectos psicanalíticos, jurídicos e sociais do perverso sexual. Rio de Janeiro: Forense, 2008.

COMTE-SPONVILLE, André. Apresentação da Filosofia. São Paulo: Martins Fontes, 2002.

FELIZARDO, Dilma; Zürcher, Eliane; e Melo, Keilla. De medo e sombra: abuso sexual contra criança e adolescente. Natal: A.S. Editores, 2003.

FERRAJOLI, Luigi. Direito e Razão: teoria do garantismo penal. $2^{\mathrm{a}}$ ed. rev. e ampl. São Paulo: Editora Revista dos Tribunais, 2006.

FERREIRA, Aurélio Buarque de Holanda. Novo Dicionário Aurélio - Século XXI, ed. Nova Fronteira, Rio de Janeiro, 2a ed, 1993.

GRECO, Rogério. Curso de Direito Penal: Parte geral. V. 1. 14ª ed. Niterói: Impetus, 2012.

GURGEL. Yara Maria Pereira. Direitos humanos, princípio da igualdade e da não discriminação: suas aplicações às relações de trabalho. 316 f. 2007. Tese (doutorado em direito das relações sociais) - Pontifícia Universidade Católica de São Paulo. Disponível em: http://www.sapientia.pucsp.br/tde_arquivos/9/TDE-2008-01-18T08:38:17Z-

4808/Publico/Yara\%20Maria\%20Pereira\%20Gurgel.pdf. Acessado em: 29 nov. 2016. 
JESUS, Damásio E. de. Penas alternativas: anotações à lei $\mathbf{n}^{\mathbf{0}} \mathbf{. 9 7 1 4}$, de 25 de novembro de 1998. $2^{a}$ ed. São Paulo: Saraiva, 2000.

MAZZUOLI, Valério de Oliveira. Curso de Direito Internacional Público. $9^{a}$ ed. rev., atual. e apl. São Paulo: Revista dos Tribunais, 2015.

MOREIRA, Ana Selma. Pedofilia: aspectos jurídicos e sociais. Leme: Cronus, 2010.

MOREIRA, Thiago Oliveira. A Aplicação dos Tratados Internacionais de Direitos Humanos pela Jurisdição Brasileira. 1ª ed. Natal: EDUFRN, 2015.

ORGANIZAÇÃO DOS ESTADOS AMERICANOS. Convenção Americana sobre Direitos Humanos (Pacto de São José da Costa Rica), adotada em 22 de novembro de 1969. Disponível em: http://www.aidpbrasil.org.br/arquivos/anexos/conv_idh.pdf. Acessado em: 15 out. 2014.

ORGANIZAÇÃO DAS NAÇÕES UNIDAS. Declaração Universal dos Direitos Humanos, adotada em 10 de dezembro de 1948. Disponível em: http://www.ohchr.org/EN/UDHR/Documents/UDHR_Translations/por.pdf. Acessado em: 19 nov. 2015.

PAIVA, U. L.; BICHARA, Jahyr-Philippe. A violação do princípio da dignidade da pessoa humana no sistema penitenciário pátrio e possibilidade de responsabilização interna e internacional do Estado brasileiro. Revista Digital Constituição e Garantia de Direitos (UFRN), v. 4, p. 1-24, 2011.

PIOVESAN, Flavia. Temas de direitos humanos. $5^{\text {a }}$ ed. São Paulo: Saraiva, 2012.

RAMOS, André de Carvalho. Curso de Direitos Humanos. São Paulo: Saraiva, 2014.

SARLET, Ingo Wolfgang (org.). Dignidade da Pessoa Humana e Direitos Fundamentais na Constituição Federal de 1988. $2^{a}$ ed. Porto Alegre: Livraria do Advogado, 2002.

THE FEASIBILITY OF PEDOPHILIANS 'RESSOCIALIZATION IN THE LIGHT OF INTERNATIONAL HUMAN RIGHTS LAW 


\begin{abstract}
Pedophilia is a serious problem faced today, especially with the advent of technology, which constitutes the most conducive environment for these individuals to hide. Society, including the judiciary, has a distorted view of pedophilia and believes that any abuser of children is a pedophile, which is not true. It is necessary to make the most adequate understanding of the subject so that the State can make the right and efficient approach. The neuralgic point of this situation is that deprivation of liberty does not have the reparative effect on these individuals, since they are not mere perverts, but of people with an intense psychiatric problem that blocks their self-determination. In this sense the best artifice for the rehabilitation of these subjects is the multidisciplinary treatment with doctors of diverse specialty and a professional psychologist, along with drug treatment, and even society and the State must be receptive to the appreciation of new outlets such as chemical castration.
\end{abstract}

Keywords: Pedophilia. Ressalization. Human dignity. Human rights. Constitutional right. 